\title{
Analysis of the Oceanic Wave Dynamics for Generation of Electrical Energy Using a Linear Generator
}

\author{
Omar Farrok, ${ }^{1,2}$ Md. Rabiul Islam, ${ }^{2}$ and Md. Rafiqul Islam Sheikh ${ }^{2}$ \\ ${ }^{1}$ Department of Electrical and Electronic Engineering, Ahsanullah University of Science \& Technology, Dhaka 1208, Bangladesh \\ ${ }^{2}$ Department of Electrical and Electronic Engineering, Rajshahi University of Engineering \& Technology, Rajshahi 6204, Bangladesh \\ Correspondence should be addressed to Omar Farrok; omarruet@gmail.com
}

Received 28 March 2016; Revised 26 May 2016; Accepted 2 June 2016

Academic Editor: Yongping Li

Copyright (c) 2016 Omar Farrok et al. This is an open access article distributed under the Creative Commons Attribution License, which permits unrestricted use, distribution, and reproduction in any medium, provided the original work is properly cited.

\begin{abstract}
Electricity generation from oceanic wave depends on the wave dynamics and the behavior of the ocean. In this paper, a permanent magnet linear generator (PMLG) has been designed and analyzed for oceanic wave energy conversion. The proposed PMLG design is suitable for the point absorber type wave energy device. A mathematical model of ocean wave is presented to observe the output characteristics and performance of the PMLG with the variation of ocean waves. The generated voltage, current, power, applied force, magnetic flux linkage, and force components of the proposed PMLG have been presented for different sea wave conditions. The commercially available software package ANSYS/ANSOFT has been used to simulate the proposed PMLG by the finite element method. The magnetic flux lines, flux density, and field intensity of the proposed PMLG that greatly varies with time are presented for transient analysis. The simulation result shows the excellent features of the PMLG for constant and variable speeds related to wave conditions. These analyses help to select proper PMLG parameters for better utilization of sea wave to maximize output power.
\end{abstract}

\section{Introduction}

At present, scientists and engineers are facing two major challenges in the world of energy: electrical energy production and environmental issue. These problems can be amicably solved using renewable energy resources (RERs). The vital factors which have stimulated the use of RERs are energy independence, financial viability, and mainly environmental protection [1]. The problem of oil crises (1973-1983) and environmental pollution concerns urged engineers to harvest electrical energy from the available RERs, for example, wind energy [2-5], solar energy [6-9], and hydro power [10]. As the RER is variable and unpredictable, different types of converters and controls are associated with the RER-based power plants that are connected with standalone or grid systems $[11,12]$. The traditional RERs have the problem of uncertainty of availability and they require a large land area. On the other hand, the key advantages of oceanic wave energy (OWE) are as follows: (i) it has huge potential compared to the solar and wind energy, (ii) it is easy to forecast, and (iii) it does not need land area. Hence, it has been of great interest to the industrial field; particularly, in energy generation, the use of wave power has been more attractive compared to other RERs [13]. OWE is a promising environmental pollution-free energy, which would make significant contribution toward saving biochemical resources and reducing carbon emissions [14]. It is estimated that the total wave energy resource in the open sea around the world is $10 \mathrm{TW}(10,000 \mathrm{GW})$, a comparable amount of the total power consumption in the world [15].

Different types of oceanic wave energy converters (WECs) have been invented and examined for successful conversion of wave energy into electrical energy [16-19]. The wave energy device may be of a rotational or a translational type and each of these devices has different features [20]. The power takeoff devices play a vital role in converting the irregular wave motion to a regular motion for energy conversion. Linear generators (LGs) have directly been implemented to the direct drive wave energy conversion without using medium devices which has unique advantages over all other wave energy devices [21]. An LG has two major parts, namely, translator and stator. The translator mounted to a hollow cylinder is sometimes called a float or floater as shown in 


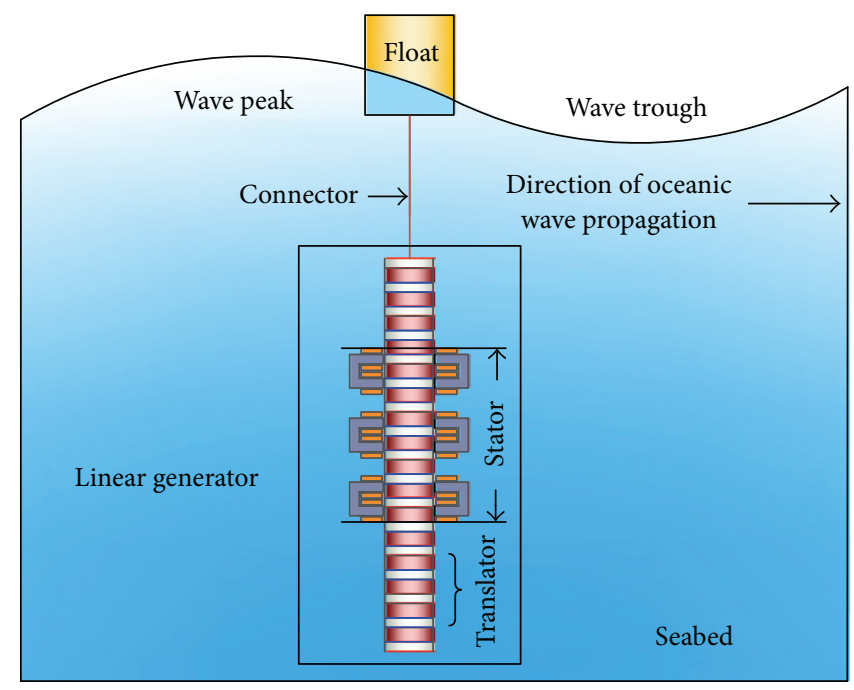

FIGURE 1: Drawing of the LG connected with a float.

Figure 1. The stator is mounted to another mechanical body in order to make it stationary with respect to the sea wave.

The floater tries to float on the surface of the ocean wave with the translator that moves relative to the stator due to wave action. The floater utilizes the rise and fall of the sea wave at a single point for energy conversion. As the translator moves linearly due to the reciprocating motion of the floater, the wave energy so extracted is converted into electrical energy. A lot of mathematicians analyzed and proposed different mathematical models for understanding the nature of oceanic wave $[22,23]$.

Different types of permanent magnet linear generators (PMLGs) have been designed and analyzed for improved performance. The flat and tubular flux switching permanent magnet linear generators (FSPMLGs) have been proposed $[21,24,25]$. Different analyses have shown that the FSPMLGs made of PMs and steel cores have suffered from the problem of higher leakage flux leading to the reduction of electrical power generation. Tubular PMLGs have been proposed [14, $21,26,27]$ to reduce cogging forces and also increase efficiency. The maintenance of tubular PMLG is difficult due to the presence of the coils inside the periphery. It is seen in the recent works [28] that the linear switched reluctance generator (LSRG) has been proposed for high power generation. Excessive leakage flux and complex control circuit of LSRGs are responsible for the degradation of overall efficiency and reliability.

This paper has presented the mathematical model of the wave motion to analyze the behavior of a PMLG that offers low internal resistance, low loading effect, and high output power. It is essential to consider the nature of wave motion for parameter selection of the PMLG, thus maximizing electricity generation. A relationship between the oceanic wave motions with the parameters of PMLG is established. Different significant parameters, for example, size of PMs, poles, translator length, and stroke length, of the PMLG are found from the relationship and the generated voltage, current, power, applied force, magnetic flux linkage, flux lines, flux

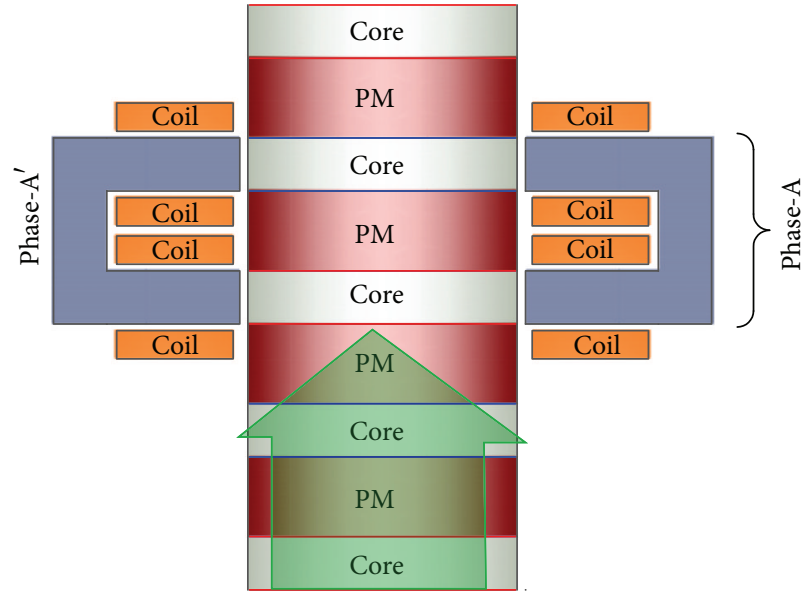

FIgURe 2: Position of the translator for time $t_{1}$.

density, and the applied force with force components of the proposed PMLG are shown for different sea wave conditions.

\section{Design of the PMLG}

2.1. Working Principle. The translator moves vertically with the incident wave; therefore, the direction may be upward or downward. Considering the translator movement in the upward direction as shown in Figures 2 and 3 for a particular time interval, the stator and translator poles are aligned facing each other. The red and green lines are representing the north pole $(\mathrm{N})$ and the south pole $(\mathrm{S})$ of the permanent magnet (PM), respectively. $\mathrm{S}$ exists in the upper side and $\mathrm{N}$ exists in the lower side of the stator core for a time $t_{1}$. The position of the translator varies with time and the direction of magnetic flux changes. The translator position changes in Figure 3 from the position shown in Figure 2. S now exists in the lower side and $\mathrm{N}$ exists in the upper side of the stator cores for another time $t_{2}$. 


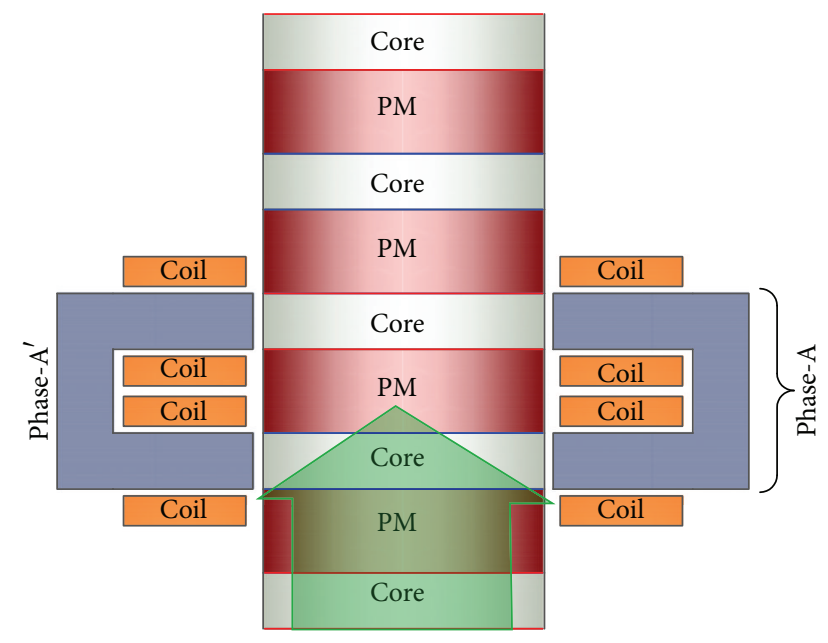

Figure 3: Position of the translator for time $t_{2}$.

Hence, the direction of magnetic flux according to Figure 2 is opposite for the translator position as in Figure 3 within the time interval $t_{2}-t_{1}$. Therefore, the induced voltage directions across the conductor are opposite to each other and due to this reason the PMLG generates AC power.

2.2. Vector Diagram and Equivalent Circuit. The winding of each phase consists of two coils of opposite phases. The induced voltages are therefore $180^{\circ}$ phase shifted to each other. The coils of each phase are connected in series in additive polarity to get higher output voltage. The vector diagrams of induced voltages are represented in Figure 4.

The equivalent circuit diagram of the proposed PMLG for a three-phase load is shown in Figure 5. The equivalent series resistances and inductances of each phase winding coil are considered equal, denoted by $R_{a}$ and $L_{S}$, respectively. The winding consists of two series coils; therefore, the equivalent series resistance and inductance of each coil are denoted by $R_{a} / 2$ and $L_{S} / 2$, respectively. $E_{a}, E_{b}$, and $E_{c}$ are the induced voltages of phase-A, phase- $B$, and phase- $C$, respectively, for simplicity. Similarly, $E_{a}^{\prime}, E_{b}^{\prime}$, and $E_{c}^{\prime}$ are the induced voltages of phase- $\mathrm{A}^{\prime}$, phase- $\mathrm{B}^{\prime}$, and phase- $\mathrm{C}^{\prime}$, respectively. The magnetic excitation is fed from the translator's PM array as shown in Figure 6 . The terminal voltages, $v_{a}, v_{b}$, and $v_{c}$, are measured across the load.

The induced voltage equation may be represented as

$$
\begin{aligned}
E_{i}+E_{i}^{\prime} & =R_{i} i_{i}+L_{S} \frac{d i_{i}}{d t}+v_{i} \\
& =K_{m} \cos \left(\frac{\pi}{\tau} z+j \frac{2 \pi}{3}\right) v_{v}(t),
\end{aligned}
$$

where $i=\mathrm{A}, \mathrm{B}$, and $\mathrm{C}, j=0,1$, and $-1, v_{i}$ is the terminal voltage, $i_{i}$ is the line current, and $L_{S}$ is synchronous inductance. $K_{m}$ is the constant representing the machine construction; $v_{v}(t)$ is the translator vertical velocity or speed; $\tau$ is the pole pitch; and $z$ is the vertical displacement. The terminal voltage is

$$
\vec{V}_{i}=\vec{E}_{i}+\vec{E}_{i}^{\prime}-j X_{S} \vec{I}_{i}-R_{i} \vec{I}_{i}
$$

2.3. Construction Details. The vertical cross section of the PMLG (front side) is shown in Figure 6. The PMLG basically contains a translator which is made by some PMs with the steel core. The stator contains some copper coils wounded on the stator cores of steel situated on both sides of the translator. Phase- $A$, phase- $B$, and phase- $C$ are located on the right side of the translator. Phase- $\mathrm{A}^{\prime}$, phase- $\mathrm{B}^{\prime}$, and phase- $\mathrm{C}^{\prime}$ are located on the left side of the translator which are $180^{\circ}$ phase shifted from phase- $A$, phase- $B$, and phase- $C$, respectively. The construction supports the translator to move in the vertical direction with respect to the stator. The orientation of the PM array should be such that $\mathrm{N}$ and $\mathrm{S}$ can be formed one after another as shown in Figure 6.

\section{Model of the Oceanic Wave}

In most of the cases, constant speeds or sinusoidal speeds having sinusoidal shapes are common approximations for simulating PMLGs [25-27]. The typical range of vertical velocity of wave is $0-2 \mathrm{~m} / \mathrm{s}$ with a time period from 4 to $6 \mathrm{~s}$ [28-30]. Therefore, a free oceanic wave neither forced nor dissipated on a flat seabed is presented for analysis of the LG as shown in Figure 7 following the mentioned approximations. The amplitude of waveform is $A$. Hence, the vertical distance between the wave crest and the trough is $H$ which is equal to twice the amplitude $A$. According to the point of view of oceanographers, it is considered as a linear wave. The sea surface is lying on $x y$ plane, where $y$ components are considered zero as the wave propagates in $x$-direction, $\lambda$ is wavelength, $d_{W}$ is water depth of the ocean with respect to $x y$ plane or water surface, seabed is at $z=-d_{W}$, and the ocean surface coincides with $z=0$.

3.1. Generalized Wave. The general description of almost any type of oceanic wave may be considered as, depending only on the interpretation of $\zeta$,

$$
\begin{aligned}
& \zeta=A \cos (k x-\omega t) \\
& \omega=\sqrt{g k \tanh \left(k d_{W}\right)} .
\end{aligned}
$$

Here, the number of waves $k=2 \pi / \lambda$ and $\omega$ is the frequency that asserts the physics and describes consideration of a water wave relating frequency and wave number. Alternatively, it can be considered as a relation between the phase speed or oceanic wave velocity, $v$, and the wavelength. Considering gravitational acceleration, $g=9.8 \mathrm{~m} / \mathrm{s}^{2}$, the phase speed which is a single basic wave that moves along the $x$-direction can be expressed as

$$
v=\sqrt{\frac{g \lambda}{2 \pi} \tanh \left(\frac{2 \pi}{\lambda} d_{W}\right)} .
$$

According to (3) and (5), the wave velocity is along $x$ direction only although it has the velocity along $z$-direction. So, the velocity of oceanic wave is a vector that depends on $x, y$, and $z$ and time, $t$. To obtain a complete description of 

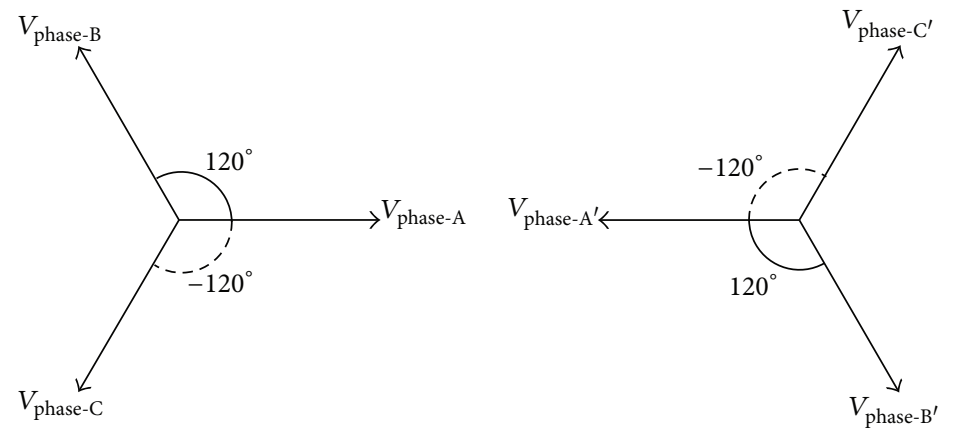

FIgURE 4: Vector diagram.

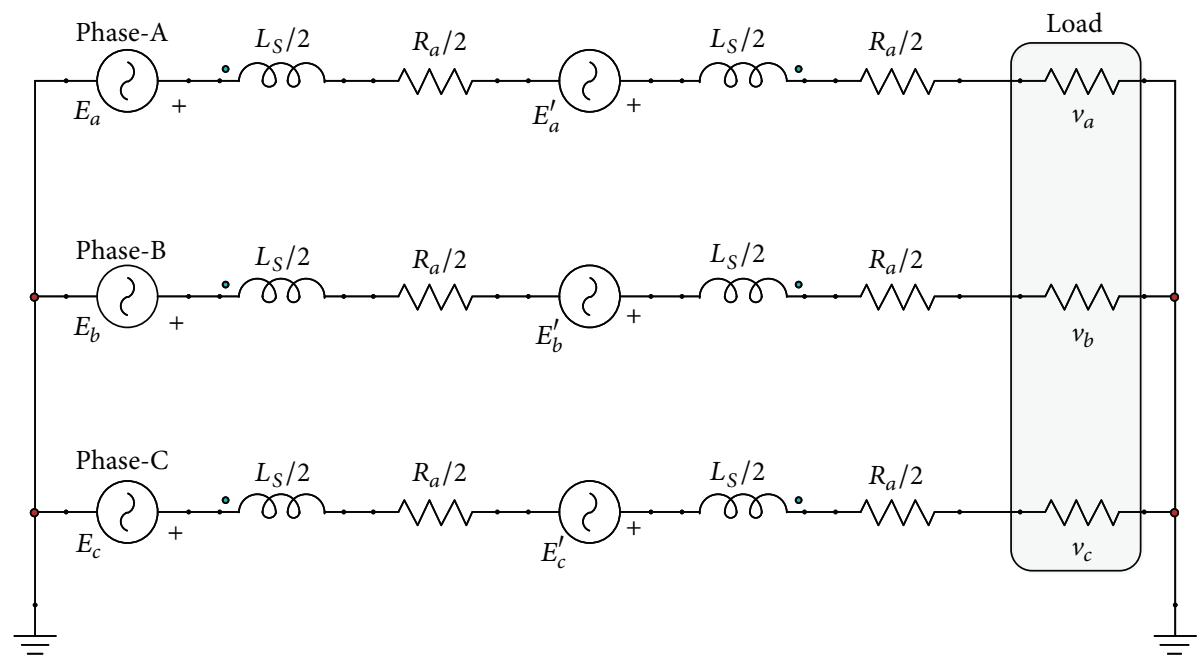

FIgURe 5: Equivalent circuit diagram of the PMLG.

oceanic wave, the components along $x, y$, and $z$ have to be calculated. The motion can be expressed as

$$
\begin{aligned}
V & (x, y, z, t) \\
& =(X(x, y, z, t), Y(x, y, z, t), Z(x, y, z, t)),
\end{aligned}
$$

where $V(x, y, z, t)$ represents the velocity of oceanic wave and $X(x, y, z, t), Y(x, y, z, t)$, and $Z(x, y, z, t)$ are the components along $x, y$, and $z$. The $y$ components may be considered as zero for the oceanic wave and the $x$ and $z$ components can be expressed as follows:

$$
\begin{aligned}
& X=A \omega \frac{\cosh \left\{k\left(z+d_{W}\right)\right\}}{\sinh \left(k d_{W}\right)} \cos (k x-\omega t) \\
& Z=A \omega \frac{\sinh \left\{k\left(z+d_{W}\right)\right\}}{\sinh \left(k d_{W}\right)} \sin (k x-\omega t) .
\end{aligned}
$$

The $x$ and $z$ components from (7) and (8) can be simplified for individual consideration of shallow water wave, intermediate depth wave, and deep sea wave.

3.2. Shallow Water Wave. In shallow water, water depth is much lower than the wavelength, $\lambda$; that is, $d_{W} \ll \lambda$ or $k d_{W} \ll 1$. Another property of shallow water wave is that the amplitude of wave is much smaller than wavelength; so, $A \ll \lambda$ or $A k \ll 1$. So, (7) and (8) may be written as

$$
\begin{aligned}
& X_{S}=A \omega \frac{e^{k\left(z+d_{W}\right)}+e^{-k\left(z+d_{W}\right)}}{e^{k d_{W}}-e^{-k d_{W}}} \cos (k x-\omega t) \\
& Z_{S}=A \omega \frac{e^{k\left(z+d_{W}\right)}-e^{-k\left(z+d_{W}\right)}}{e^{k d_{W}}-e^{-k d_{W}}} \sin (k x-\omega t) .
\end{aligned}
$$

Now, (9) and (10) may be reduced as

$$
\begin{aligned}
& X_{S} \cong \frac{A \omega}{k d_{W}} \cos (k x-\omega t) \\
& Z_{S} \cong A \omega\left(1+\frac{z}{d_{W}}\right) \sin (k x-\omega t) .
\end{aligned}
$$

Again, if $k d_{W} \ll 1, \omega=\sqrt{g k \tanh \left(k d_{W}\right)}$ can be simplified as $\omega=k \sqrt{g d_{W}}$ because

$$
\tanh \left(k d_{W}\right)=\frac{e^{k d_{W}}-e^{-k d_{W}}}{e^{k d_{W}}+e^{-k d_{W}}}=\frac{2 k d_{W}}{2}=k d_{W} .
$$

As $v=\omega / k$, phase speed can be expressed as $v=\sqrt{g d_{W}}$. 


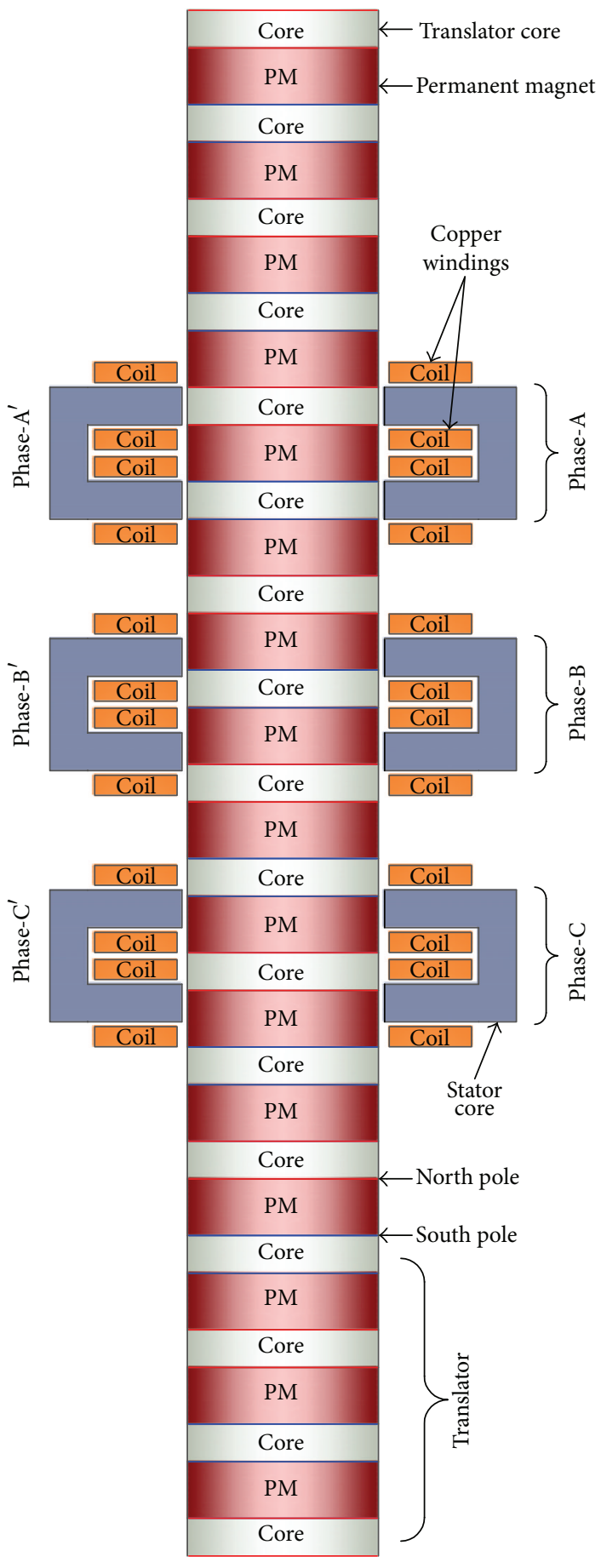

FIGURE 6: Construction of the PMLG.

3.3. Deep Water Wave. In deep water, water depth is much higher than wavelength; that is, $d_{W} \gg \lambda$ or $k d_{W} \gg 1$. So,

$$
\tanh \left(k d_{W}\right)=\frac{e^{k d_{W}}-e^{-k d_{W}}}{e^{k d_{W}}+e^{-k d_{W}}} \cong \frac{e^{k d_{W}}}{e^{k d_{W}}}=1 .
$$

$$
\begin{aligned}
& \frac{e^{k\left(z+d_{W}\right)}+e^{-k\left(z+d_{W}\right)}}{e^{k d_{W}}-e^{-k d_{W}}} \cong \frac{e^{k\left(z+d_{W}\right)}}{e^{k d_{W}}}=e^{k d_{W}}, \\
& \frac{e^{k\left(z+d_{W}\right)}-e^{-k\left(z+d_{W}\right)}}{e^{k d_{W}}-e^{-k d_{W}}} \cong \frac{e^{k\left(z+d_{W}\right)}}{e^{k d_{W}}}=e^{k d_{W}},
\end{aligned}
$$

Therefore, (7) and (8) can be expressed as follows:

$$
\begin{aligned}
& X_{D} \cong A \omega e^{k d_{W}} \cos (k x-\omega t) \\
& Z_{D} \cong A \omega e^{k d_{W}} \sin (k x-\omega t) .
\end{aligned}
$$


TABLE 1: Comparison of the oceanic wave parameters.

\begin{tabular}{lccc}
\hline Wave type & Shallow water & Intermediate depth wave & Deep water \\
\hline Relative depth & $\frac{d_{W}}{\lambda}<0.05$ & $0.05<\frac{d_{W}}{\lambda}<0.5$ & $\frac{d_{W}}{\lambda}>0.5$ \\
Wave speed & $\sqrt{g d_{W}}$ & $\sqrt{\frac{g \lambda}{2 \pi} \tanh \left(2 \pi \frac{d_{W}}{\lambda}\right)}$ & $\sqrt{\frac{g \lambda}{2 \pi}}$ \\
Wave length & $\sqrt{g d_{W} T}$ & $\frac{g T^{2}}{2 \pi} \tanh \left(2 \pi \frac{d_{W}}{\lambda}\right)$ & $\frac{g T^{2}}{2 \pi}$ \\
\hline
\end{tabular}

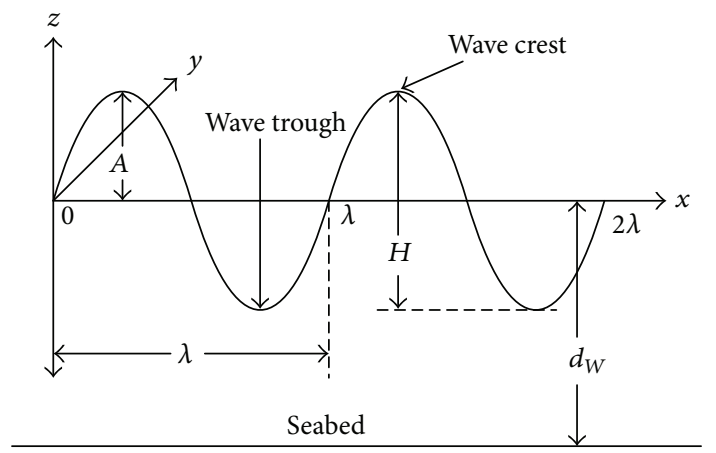

FIGURE 7: Waveform of a free oceanic wave.

Again, if $k d_{W} \gg 1, \omega=\sqrt{g k \tanh \left(k d_{W}\right)}$ can be simplified as $\omega=\sqrt{g k}$. Phase speed, $v$, can be expressed as $v=\sqrt{g / k}$. The $x$ and $z$ components, both for shallow and for deep water from (6)-(12), (15), and (16), are explained in [31]. Comparisons of relative depth, wave speed, and wavelength of shallow water wave, intermediate depth wave, and deep sea wave are shown in Table 1.

\section{The PMLG and Wave Model}

4.1. Selection of Translator Length. The translator lengths may be shorter, equal, or longer compared to the stator. The common lengths of the stator and the translator affect the power rating of the PMLG. The power rating increases with increase in the common length. Longer translator has been chosen to obtain the same common length as shown in Figure 8 for different translator positions. The vertical displacement of translator with the incident sea wave is known as stroke length, $L_{\text {st }}$. There is a relationship between the wave amplitude, $A_{w}$, and $L_{\text {st }}$ during the energy conversion as $L_{\mathrm{st}}=2 A_{w}$. $A_{w}$ is smaller than the amplitude of free oceanic wave as in (7)-(12), (15), and (16) because of power dissipation.

4.2. Determination of Frequency. The translator pole pitch is the summation of the PM thickness and translator pole thickness of the PMLG as shown in Figure 9. The stator pole pitch and translator pole pitch may be the same or different depending on the design strategy. In the proposed design, the stator pole pitch is the same as the translator pole pitch and the stator pole width is the same as the translator pole width. The pitch and pole width have a vital effect on the generated voltage, shape, power, frequency, and forces. The frequency, $f$, of the PMLG is determined by

$$
f=\frac{v_{v}(t)}{2 \tau} .
$$

4.3. Direction of Forces. The simulation setup of the PMLG design is represented using a 3D Cartesian coordinate system. The applied force is working along $z$-axis, as shown by bidirectional arrow in Figure 10. The width and thickness of this design are along $y$-axis and $x$-axis, respectively. Cogging forces between stator and translator core act along $y$-axis. Other force components except for applied force and cogging forces work along $x$-axis. The PMLG converts mechanical energy to electrical energy due to the force along $z$-axis and the forces along $x$-axis and $y$-axis are generated which is the cause of mechanical power loss. In the oceanic wave model, the direction of wave elevation is also along $z$-axis according to (8), (10), (12), and (16).

4.4. Generated Voltage with Waves. According to Faraday's law of electromagnetic induction, the induced voltage is found as

$$
E_{i}(t)=-N \frac{d \vec{\Phi}}{d t} .
$$

In the wave model, the wave elevation is described with respect to $x$-axis that represents the direction of wave propagation. The induced voltage and related parameters of the PMLG are related to time. The vertical wave displacement is assumed to be sinusoidal and the translator connected to buoy tries to follow the wave elevation; therefore, the vertical displacement, $d_{\mathrm{tr}}$, and velocity, $s_{\mathrm{tr}}$, of the translator can be expressed as given in (19) and (20), respectively [14]. Hence,

$$
\begin{aligned}
& d_{\mathrm{tr}}(t)=A_{w} \sin \left(\frac{2 \pi}{T} t \pm \theta_{i}\right) \\
& s_{\mathrm{tr}}(t)=A_{w} \frac{2 \pi}{T} \cos \left(\frac{2 \pi}{T} t \pm \theta_{i}\right) .
\end{aligned}
$$

Here, $A_{w}, \theta_{i}$, and $T$ represent wave amplitude, initial phase angle, and period of oceanic wave, respectively. The translator and buoy move with the wave elevation; therefore, the flux variation with respect to time can be expressed as

$$
\Phi(t)=\vec{\Phi} \frac{2 \pi}{\lambda} d_{\mathrm{tr}}(t)
$$




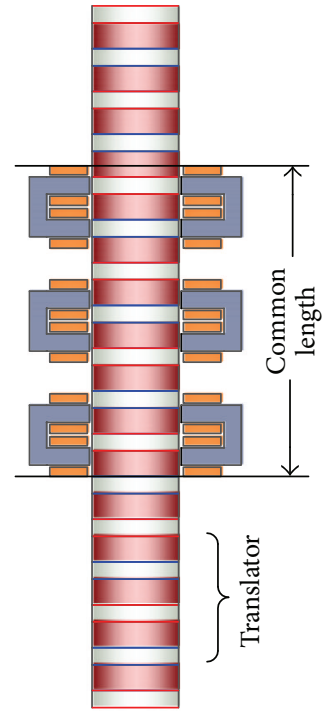

(a)

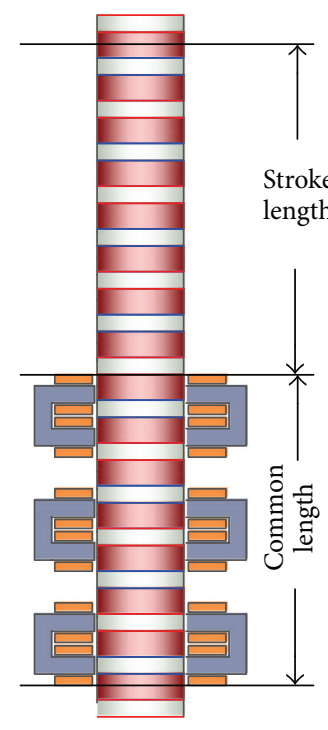

(b)

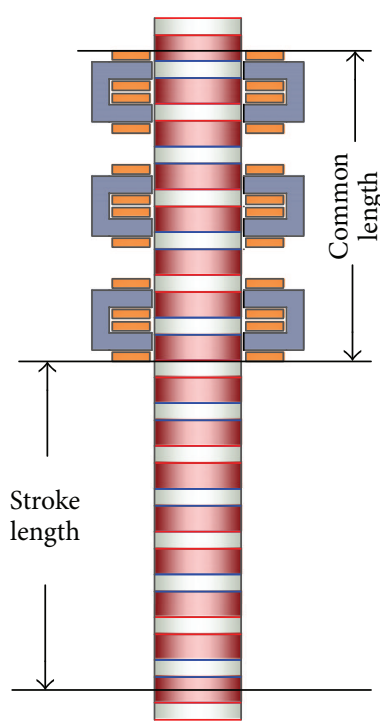

(c)

FIgURE 8: Translator position at different time.

If $V_{m}$ is the peak voltage, combining (18) and (21), the generated EMF per phase and $V_{m}$ of the PMLG, $v_{\mathrm{lg}}$, are obtained as [32]

$$
\begin{aligned}
v_{\mathrm{lg}}(t) & =\vec{V}_{m} \cos \left(\frac{2 \pi}{T} t\right) \cos \left\{\frac{2 \pi A_{w}}{\lambda} \sin \left(\frac{2 \pi}{T} t\right)\right\} \\
V_{m} & =N \vec{\Phi} \frac{2 \pi}{\lambda} \frac{2 \pi}{T} A_{w} .
\end{aligned}
$$

\section{Simulation Results}

Two types of speed settings have been used in this simulation; one is consideration of constant translator speed for observation of the performance of the PMLG and the other is translator motion changed with the incident sea wave. The default air gap length is $2 \mathrm{~mm}$, load is $4 \Omega$, and the translator speed is $1 \mathrm{~m} / \mathrm{s}$ for the PMLG unless otherwise specified. The input of the PMLG is mechanical thrust, $F$, in newton. From mechanical power, $P_{m}=F \times s_{\text {tr }}$, and electrical power, $P_{e}$, efficiency, $\eta$, is calculated by $\eta=P_{e} / P_{m}$.

5.1. Constant Translator Speed. The terminal voltage and load current for default condition are shown in Figure 11.

The load voltage and current are in the same phases due to the resistive load. The applied force, $F_{z}$, cogging force, $F_{y}$, and force component along $x$-axis, $F_{x}$, are shown in Figure 12. The induced voltage, current, and magnetic flux

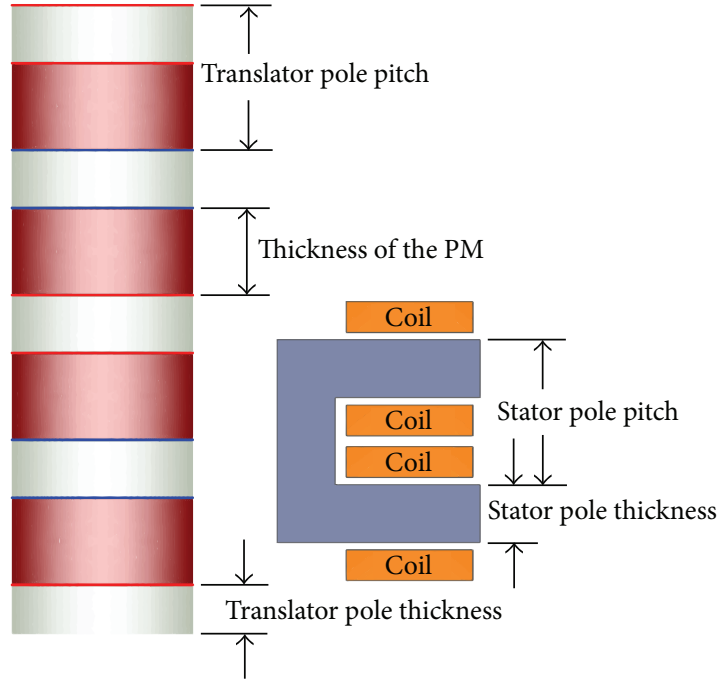

FIGURE 9: Stator and translator pole pitch.

linkage are shown in Figure 13. The generated power is shown in Figure 14.

5.2. Voltage Regulation. The terminal voltage depends on the load for a specific PMLG as in (2), which is shown in Figure 15 to observe the terminal characteristics. 
TABLE 2: Numerical values for legend of Figure 16.

\begin{tabular}{lcccc}
\hline Legend name & Load $(\Omega)$ & RMS current $(\mathrm{A})$ & DC offset $(\mathrm{A})$ & Period $(\mathrm{ms})$ \\
\hline$I_{1}$ & 4 & 8.6656 & 0.0377 & 79.9355 \\
$I_{2}$ & 5 & 7.1327 & 0.0269 & 81.7782 \\
$I_{3}$ & 8 & 4.6401 & 0.0151 & 81.2897 \\
$I_{4}$ & 10 & 3.7586 & 0.0118 & 81.1431 \\
$I_{5}$ & 15 & 2.5455 & 0.0077 & 80.85 \\
$I_{6}$ & 20 & 1.9233 & 0.0057 & 80.7523 \\
\hline
\end{tabular}

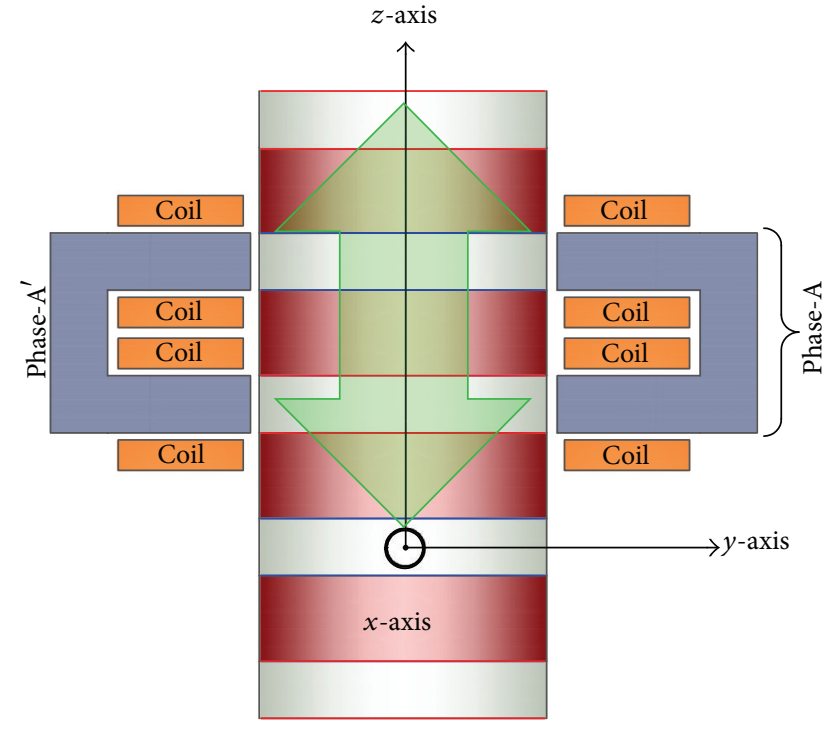

FIgURE 10: Direction of different forces.

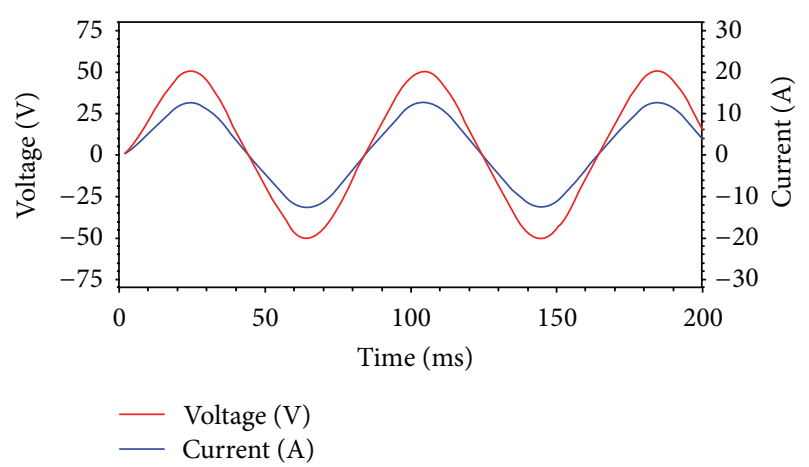

FIGURE 11: Load voltage and current waveforms.

Different loads ranging from $2 \Omega$ up to $1 \mathrm{M} \Omega$ are shown on a semilog graph. Load voltages measured from any one of the three phases are similar and remain almost unchanged from $25 \Omega$ to $1 \mathrm{M} \Omega$. The RMS values of currents and power of phase-A for different load conditions are shown in Figures 16 and 17, respectively. The numerical values of the current and power graphs used in the legend are tabulated in Tables 2 and 3 , respectively.

5.3. Variable Translator Speed. According to the oceanic wave model, the vertical position of the wave is sinusoidal, so the

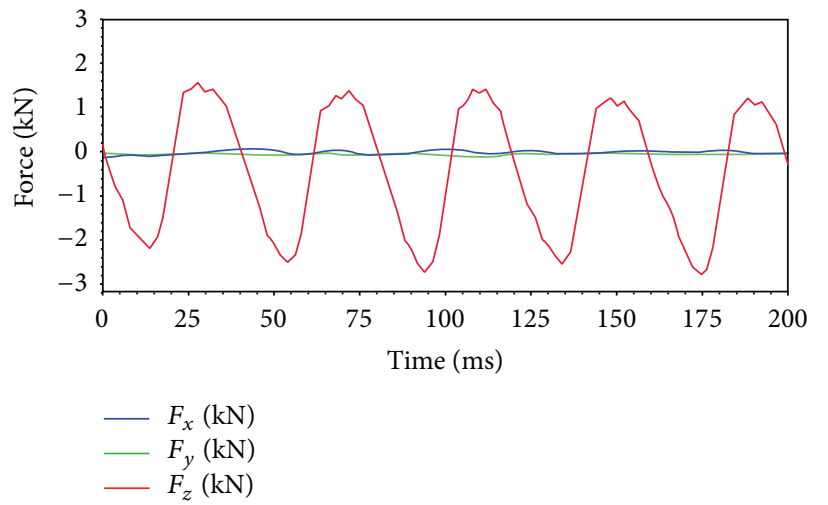

Figure 12: Different forces of the PMLG.

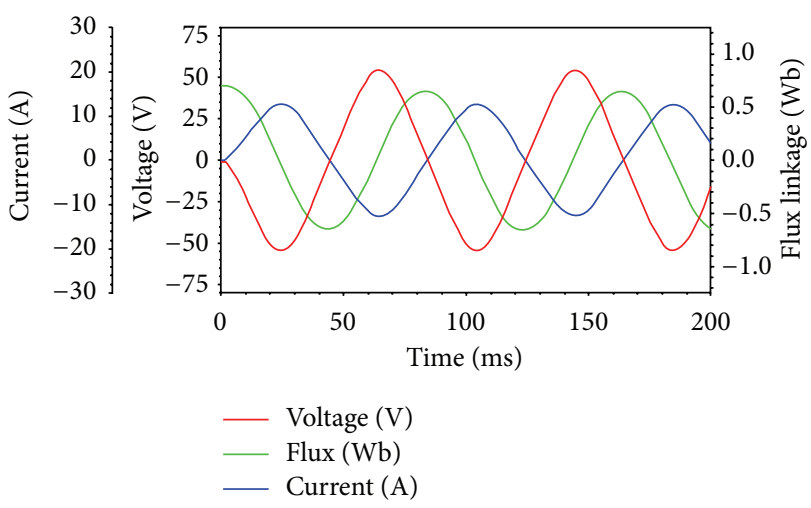

FIGURE 13: Induced voltage, current, and flux linkage.

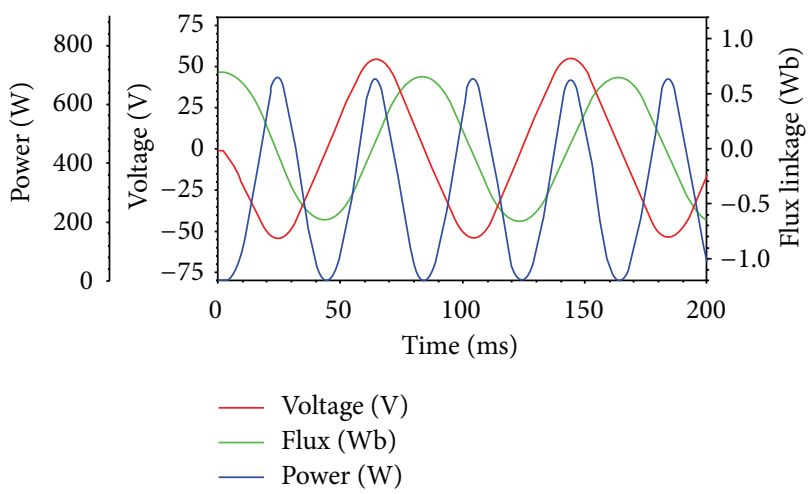

FIGURE 14: Generated power with voltage and flux. 
TABLE 3: Numerical values for legend of Figure 17.

\begin{tabular}{lcccc}
\hline Legend name & Load $(\Omega)$ & RMS power $(\mathrm{W})$ & Period $(\mathrm{ms})$ & Maximum power $(\mathrm{W})$ \\
\hline$P_{1}$ & 4 & 242.0785 & 40.0733 & 691.9896 \\
$P_{2}$ & 5 & 204.3384 & 40.0488 & 586.9683 \\
$P_{3}$ & 8 & 137.9347 & 40.0488 & 398.2045 \\
$P_{4}$ & 10 & 113.0125 & 40.0366 & 328.8075 \\
$P_{5}$ & 15 & 77.636 & 40.0366 & 228.3736 \\
$P_{6}$ & 20 & 59.0638 & 40.0244 & 174.9611 \\
\hline
\end{tabular}

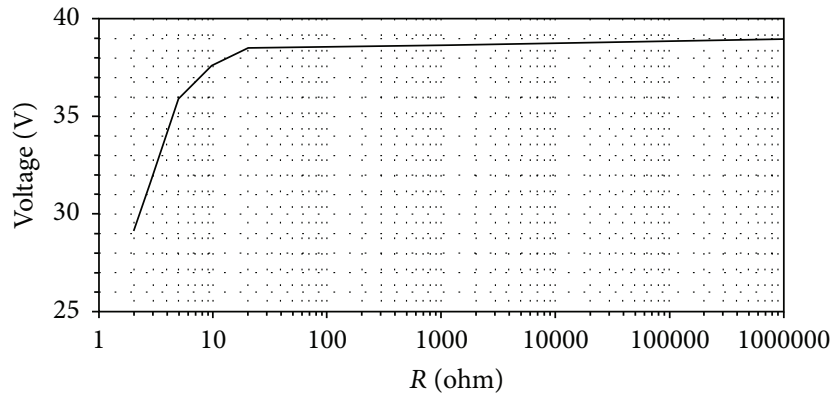

FIGURE 15: Terminal voltage for different loads.

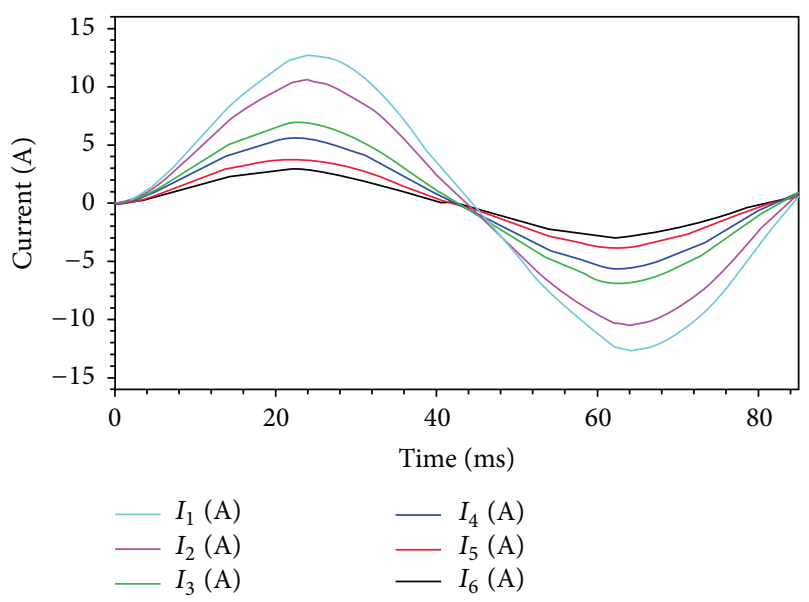

FIGURE 16: Load currents for different loads.

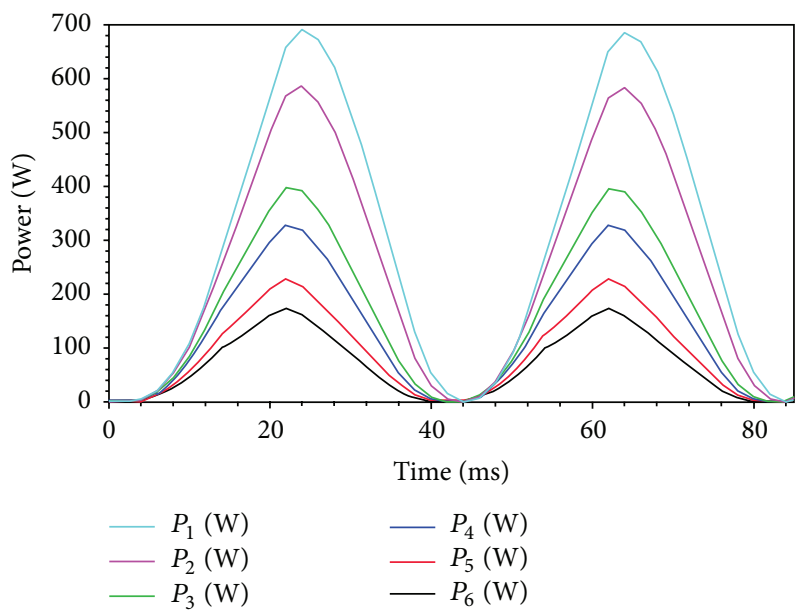

FIgURE 17: Generated power for different loads.

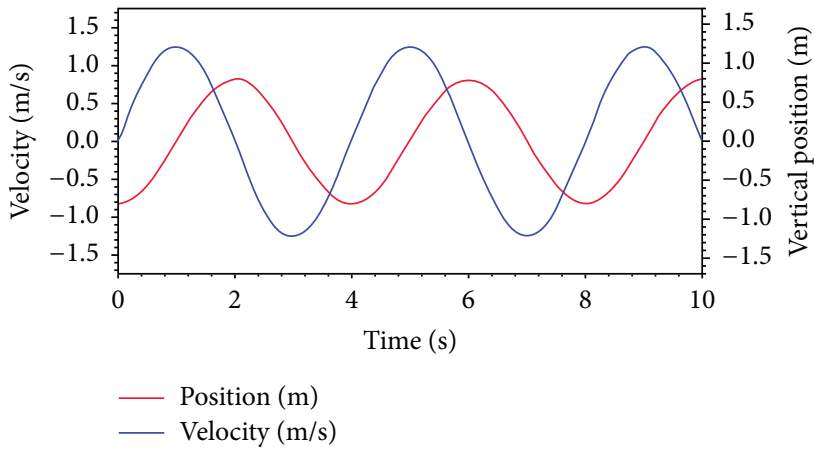

FIgURE 18: Position and velocity of the translator.

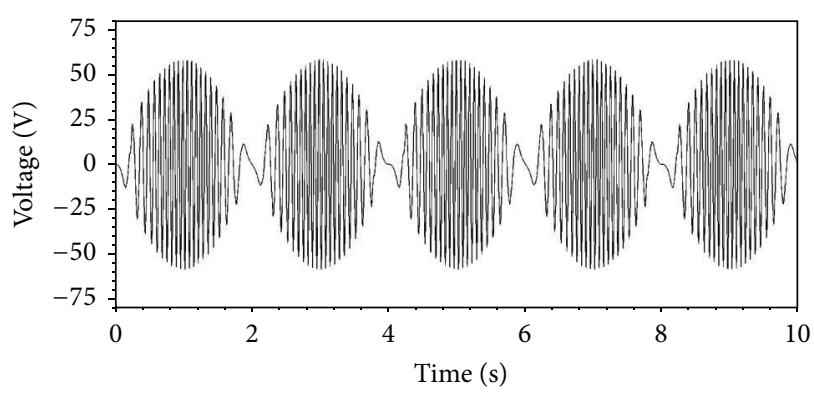

FIGURE 19: Generated voltage.

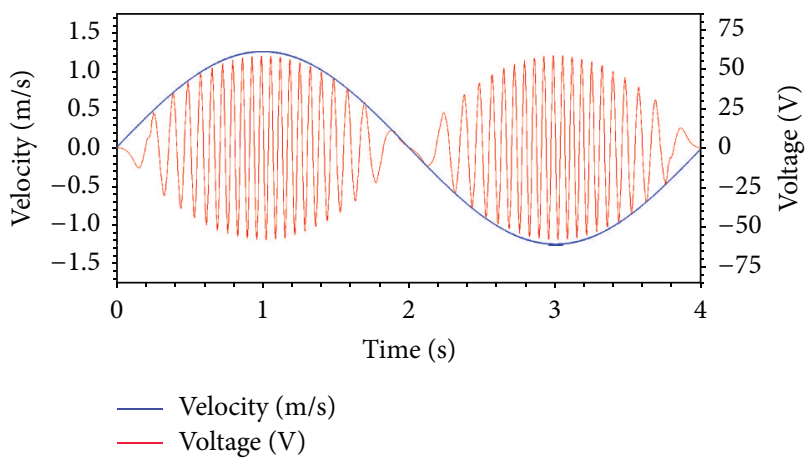

Figure 20: Relation between induced voltage and speed.

vertical velocity of the wave elevation is a cosine function. The vertical position and velocity of the translator are shown in Figure 18. The time period $T=4 \mathrm{~s}$ and $L_{S}=1.6 \mathrm{~m}$ which means $A_{w}=0.8 \mathrm{~m}$. The magnitude of the generated voltage of 


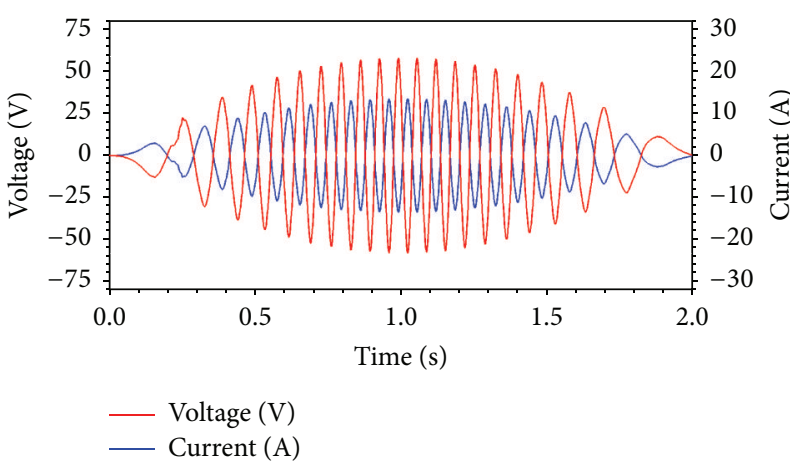

Figure 21: The induced voltage and current.

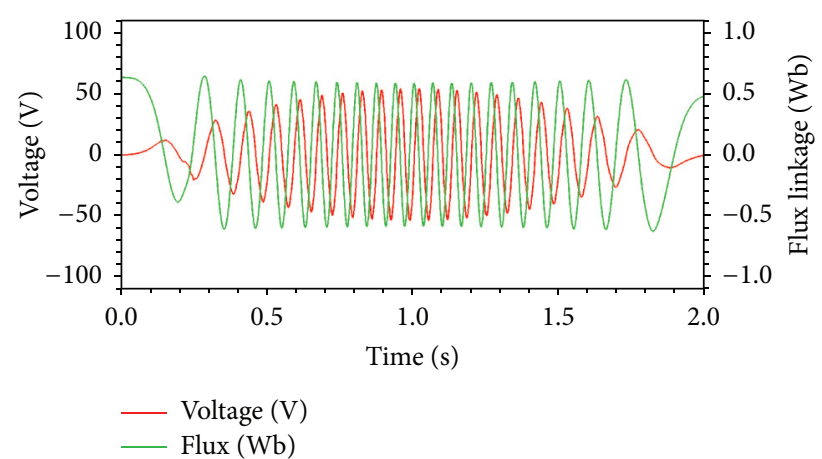

Figure 22: Magnetic flux linkage and terminal voltage.

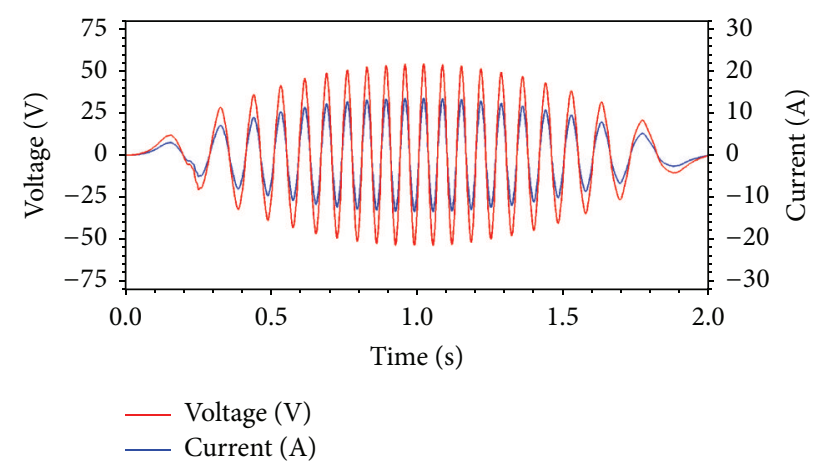

FIgURE 23: Terminal voltage and current.

the PMLG depends on velocity according to (20) and is shown in Figure 19.

As $T=4 \mathrm{~s}$, the voltage waveform is repeated in each half cycle or $T / 2=2 \mathrm{~s}$ as shown in Figure 19. The voltage waveform due to the translator velocity for the time period of one cycle is shown in Figure 20. The induced voltage and current for a half-cycle time interval are shown in Figure 21. The terminal voltage lags by $90^{\circ}$ from the magnetic flux linkage as shown in Figure 22.

The voltage magnitude is directly proportional to the translator velocity. According to (17) and (20), the frequency of voltage increases with the increase in velocity. The terminal voltage and current in a winding are shown in Figure 23. The cogging force is the reason of force ripples and is liable for

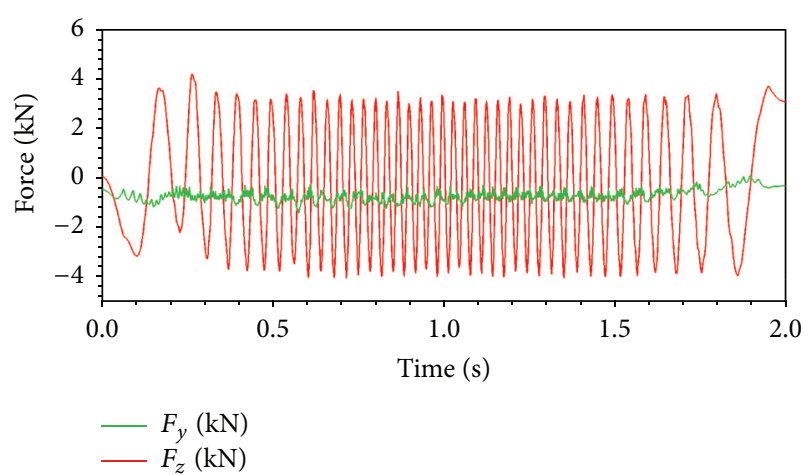

Figure 24: Different forces of the PMLG.

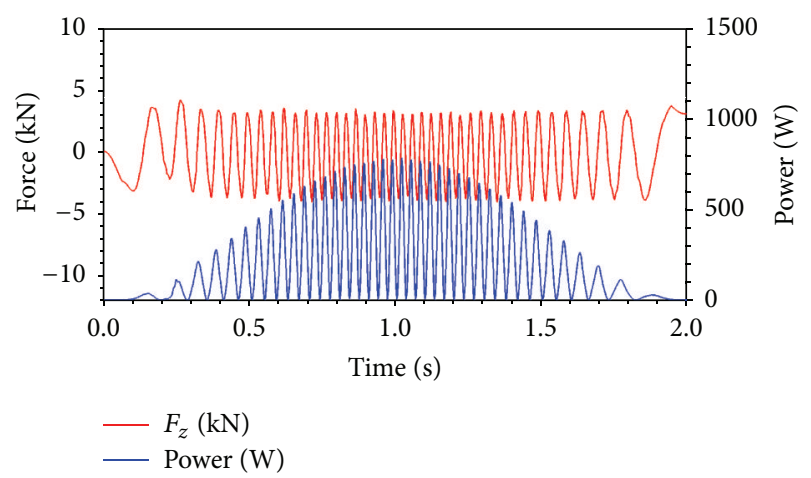

FIGURE 25: Applied force and power.

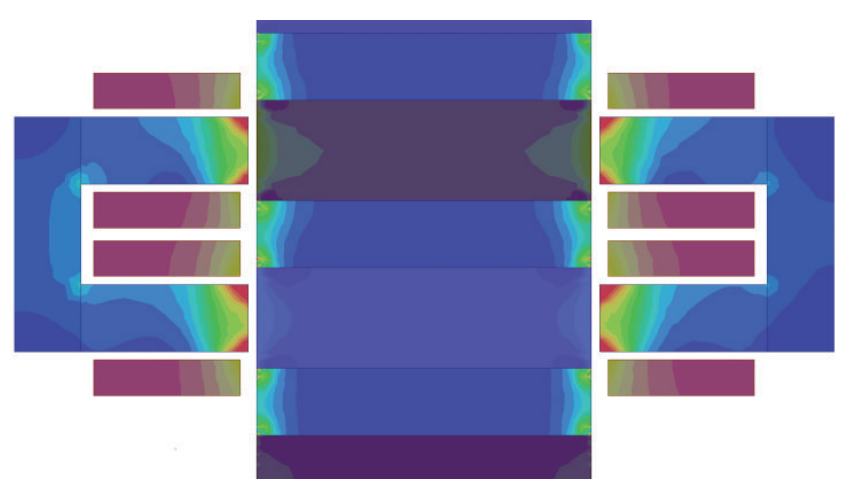

FIgUre 26: Magnetic flux density at $t=20 \mathrm{~ms}$.

abnormal operation of the PMLG, so it is maintained at a lower value as shown in Figure 24 with the applied force. The magnitude of power is related to the frequency. The power generation due to the applied force is shown in Figure 25.

Different dimensions of the PMLG active materials of the stator and translator as shown in Figure 6 are given in Table 4. The significant parameters that mainly affect the PMLG performance are given in Table 5.

5.4. Selection of the PM Size. According to Figure 18, the vertical displacement of the translator is $1.6 \mathrm{~m}$ owing to the minimum and maximum vertical displacement of $-0.8 \mathrm{~m}$ and $0.8 \mathrm{~m}$, respectively. On the other hand, the translator 


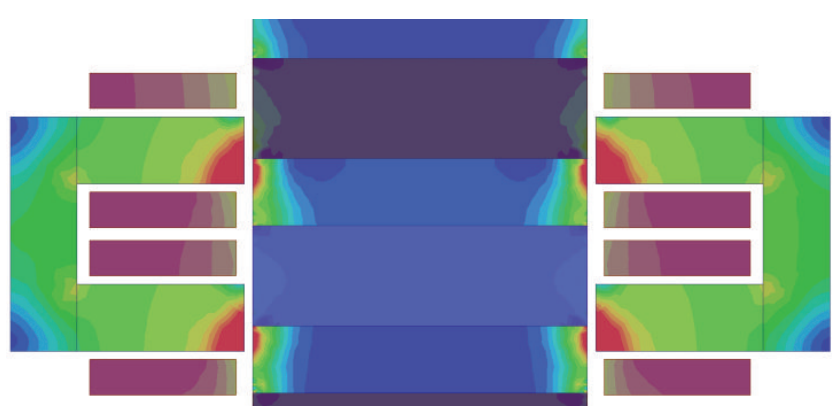

Figure 27: Magnetic flux density at $t=30 \mathrm{~ms}$.
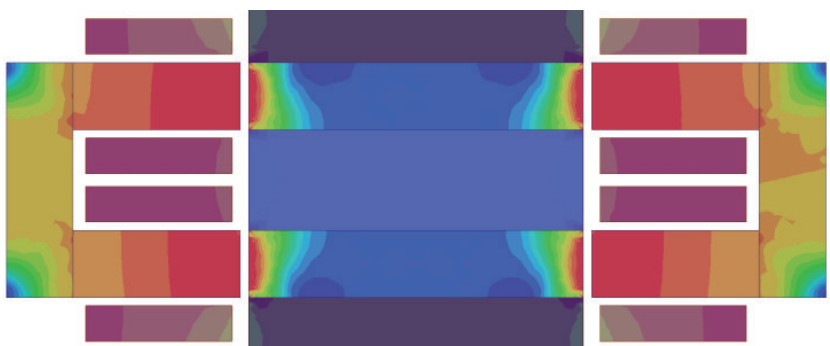

Figure 28: Magnetic flux density at $t=40 \mathrm{~ms}$.

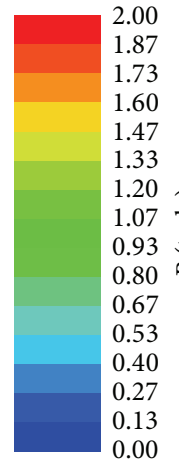

(a)

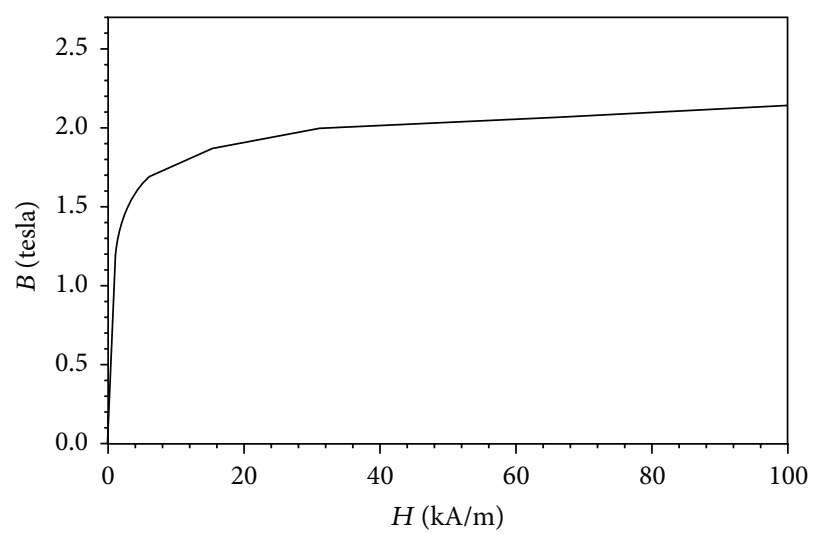

(b)

Figure 29: (a) Scale of $B$ and (b) magnetizing curve.

TABle 4: Dimensions of the PMLG.

\begin{tabular}{lcc}
\hline Name of the item & Value & Unit \\
\hline Width of the translator & 8 & $\mathrm{~cm}$ \\
Width of the stator & 5.6 & $\mathrm{~cm}$ \\
Width of the PMLG & 19.6 & $\mathrm{~cm}$ \\
Thickness of pole shoe & 1.6 & $\mathrm{~cm}$ \\
Depth of the PMLG & 10 & $\mathrm{~cm}$ \\
Thickness of PM & 2.4 & $\mathrm{~cm}$ \\
Cross section of the conductor & 2.5 & $\mathrm{~mm}^{2}$ \\
Stroke length & 1.6 & $\mathrm{~m}$ \\
\hline
\end{tabular}

length is the summation of stator length and stroke length. Combining the stroke length of $1.6 \mathrm{~m}$ and the stator length of $1.4 \mathrm{~m}$, the translator length becomes $3 \mathrm{~m}$. From Table 5, the translator and stator pole pitch is $4 \mathrm{~cm}$ which is the summation of the PM and the pole thickness. Therefore, 75 PMs and poles are required to make $3 \mathrm{~m}$ length of translator. The dimension of the translator PMs is selected as $8 \times 10 \times 2.4 \mathrm{~cm}$.

\section{Analysis of Magnetic Flux}

The magnetic flux density, $B$, flux lines, and magnetic field intensity of the PMLG are analyzed to observe $B$ in the different portions. The value of $B$ for different time, $t$, is shown in Figures 26-28. $B$ varies for different positions of the translator which can be realized from the scale given in Figure 29(a). The magnetizing curve of the steel used in the stator and translator core is shown in Figure 29(b). 


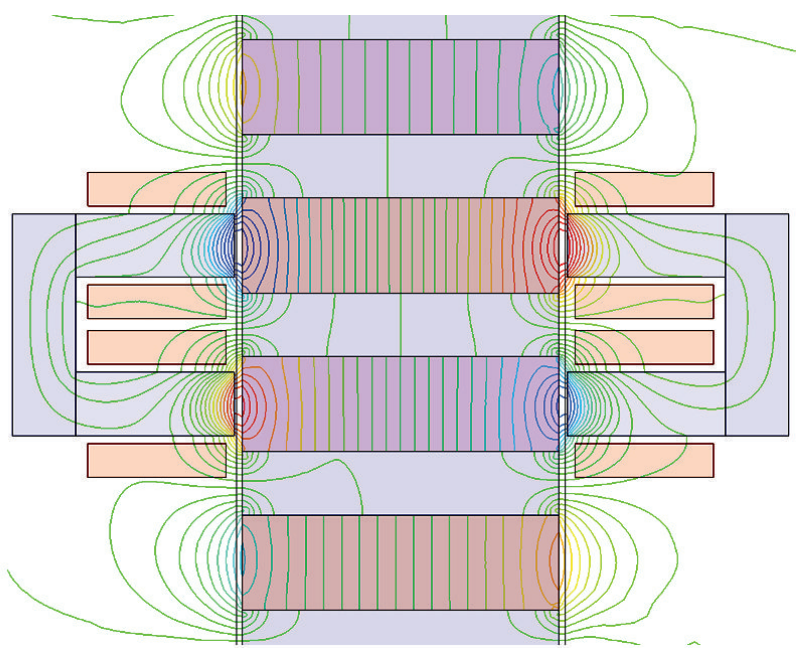

Figure 30: Magnetic flux at $t=20 \mathrm{~ms}$.

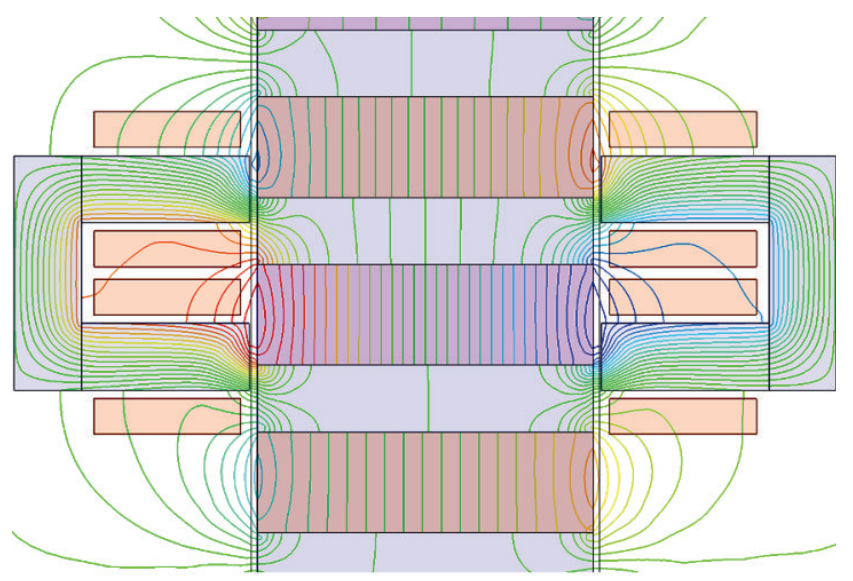

FIgURE 31: Magnetic flux at $t=30 \mathrm{~ms}$.

The translator position varies with time and the flux lines travel through the low reluctance path. The magnetic flux lines for different times are shown in Figures 30-32.

There is a relation between magnetic flux lines and $B$. Figures 33(a)-33(c) represent the scale of flux lines for $t=$ $20 \mathrm{~ms}, 30 \mathrm{~ms}$, and $40 \mathrm{~ms}$, respectively. The magnetic properties inside the PMLG are needed for analyses, proper design, and performance check.

The values for the magnetic field intensity at different times are shown in Figures 34-36 and the scale is shown in Figure 37 . The magnetomotive force mainly exists in the air gap. When the stator and translator cores come close together, the magnetomotive force reaches a high value. Neodymium iron boron $(\mathrm{NdFeB})$ permanent magnets have been used for magnetic excitation.

\section{Conclusions}

The simulation results with synchronized translator vertical velocity with wave velocity reflect the model presented in this paper. Different voltages, currents, power, and magnetic
TABLE 5: The parameters of the PMLG.

\begin{tabular}{lcc}
\hline Name of the item & Value & Unit \\
\hline Pole pitch of translator and stator & 4 & $\mathrm{~cm}$ \\
Pitch factor of pole shoe & 0.4 & \\
Turn number of copper coil & 70 & Turns \\
Number of coils in a winding & 2 & \\
Winding factor & 0.6 & \\
Velocity/speed of the translator & $0-1.5$ & $\mathrm{~m} / \mathrm{s}$ \\
Air gap length & 2 & $\mathrm{~mm}$ \\
Internal resistance of windings & 0.3 & $\Omega$ \\
Load resistance & $2-25$ & $\Omega$ \\
Maximum power (depends on some factors) & $175-692$ & $\mathrm{~W}$ \\
\hline
\end{tabular}

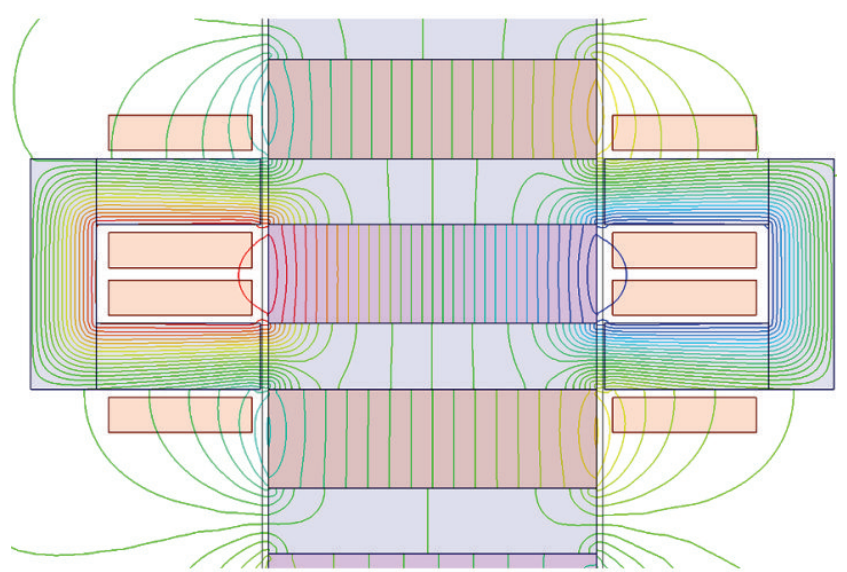

Figure 32: Magnetic flux at $t=40 \mathrm{~ms}$.

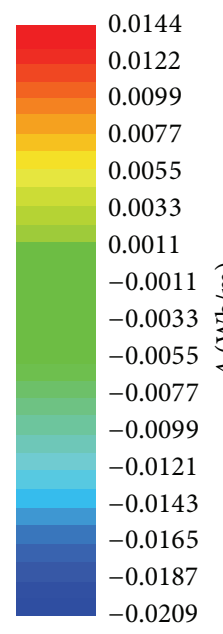

(a)

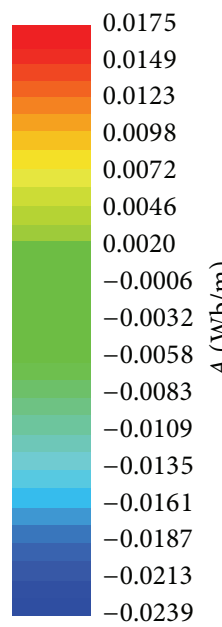

(b)

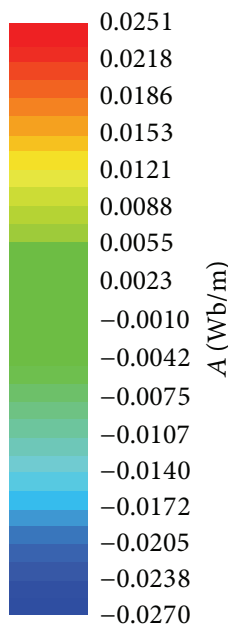

(c)
Figure 33: Scale of magnetic flux.

flux linkages of phase-A are shown for the three-phase PMLG because the other two phases are just $120^{\circ}$ phase shifted from each other and are not necessary to explain the dynamics of energy conversion from wave energy to electrical energy. The cogging force and force ripples are low compared to applied force that helps to prevent mechanical vibration and also 


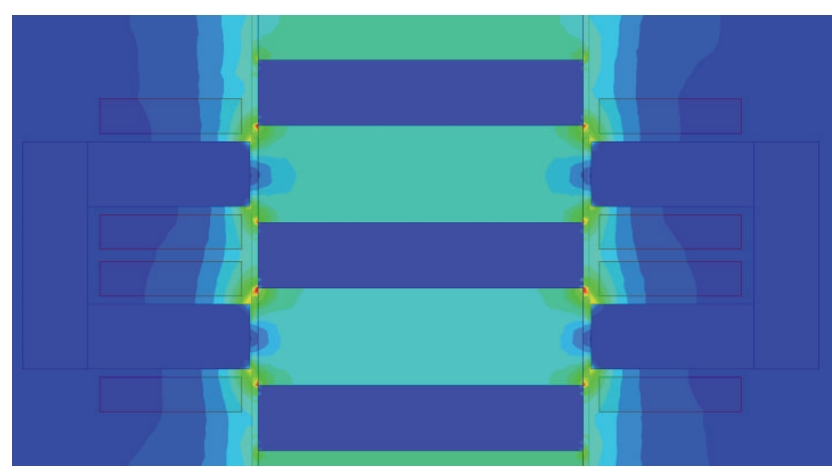

Figure 34: Magnetic field intensity at $t=20 \mathrm{~ms}$.

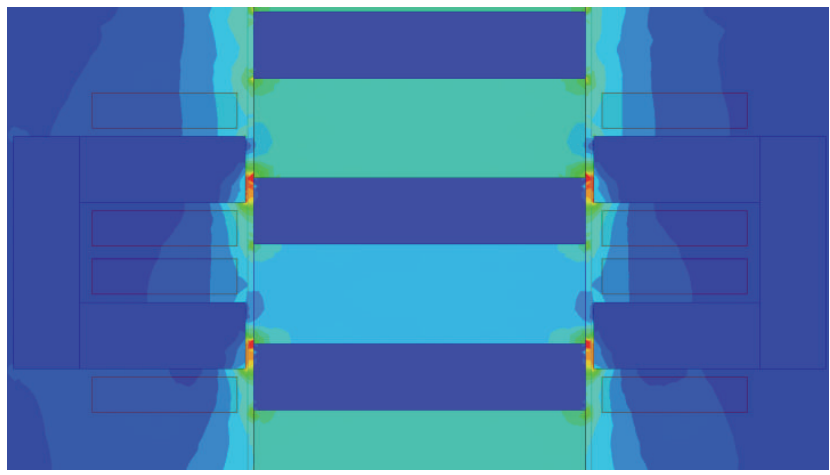

FIgUre 35: Magnetic field intensity at $t=30 \mathrm{~ms}$.

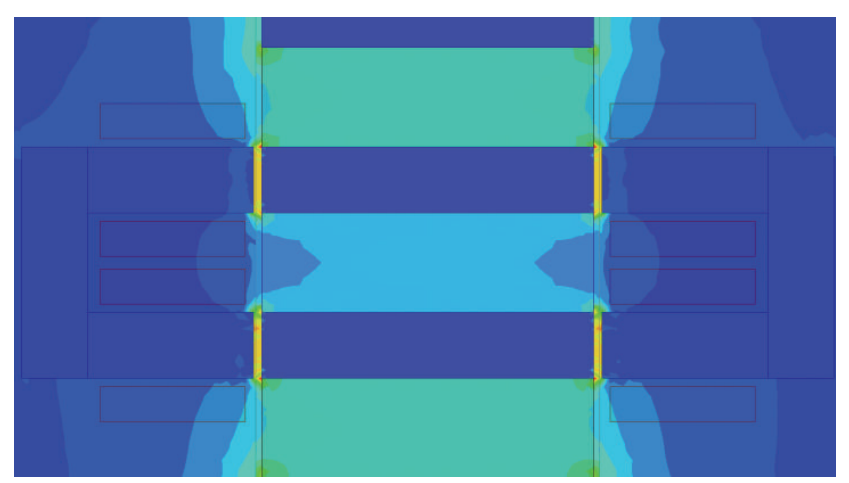

FIgURE 36: Magnetic field intensity at $t=40 \mathrm{~ms}$.

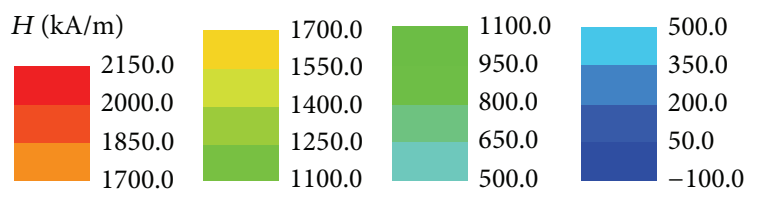

FIGURE 37: Scale of $H$.

minimize mechanical power loss. Low core loss is achieved (1.27\%) which would produce less heat to prevent overheating of the PMLG and increase service life. The maximum efficiency is calculated as $83 \%$ for full-load condition. The loading effect is low and voltage regulation of the PMLG is $13.93 \%$ measured from terminal characteristics. Thick copper conductor with smaller turn number is used in the coil to minimize internal resistance.

\section{Competing Interests}

The authors declare that there are no competing interests regarding the publication of this paper.

\section{References}

[1] H. Polinder, M. E. C. Damen, and F. Gardner, "Linear PM generator system for wave energy conversion in the AWS," IEEE Transactions on Energy Conversion, vol. 19, no. 3, pp. 583-589, 2004.

[2] P. Tokat, T. Thiringer, and P. Chen, "Development of an analytically described pitch regulator for a wind turbine to be used for grid disturbance studies," Journal of Energy, vol. 2013, Article ID 203174, 9 pages, 2013.

[3] K. Mohammadi, A. Mostafaeipour, Y. Dinpashoh, and N. Pouya, "Electricity generation and energy cost estimation of large-scale wind turbines in Jarandagh, Iran," Journal of Energy, vol. 2014, Article ID 613681, 8 pages, 2014.

[4] M. R. Islam, Y. Guo, J. G. Zhu, H. Y. Lu, and J. X. Jin, "Highfrequency magnetic-link medium-voltage converter for superconducting generator-based high-power density wind generation systems," IEEE Transactions on Applied Superconductivity, vol. 24, no. 5, Article ID 5202605, 2014.

[5] B. Jain, S. Singh, S. Jain, and R. K. Nema, "Flexible mode control of grid connected wind energy conversion system using wavelet," Journal of Energy, vol. 2015, Article ID 152898, 12 pages, 2015.

[6] A. O. Adelaja and B. I. Babatope, "Analysis and testing of a natural convection solar dryer for the tropics," Journal of Energy, vol. 2013, Article ID 479894, 8 pages, 2013.

[7] M. R. Islam, Y. G. Guo, and J. G. Zhu, "A multilevel mediumvoltage inverter for step-up-transformer-less grid connection of photovoltaic power plants," IEEE Journal of Photovoltaics, vol. 4, no. 3, pp. 881-889, 2014.

[8] J. Basheer Sheeba and A. Krishnan Rohini, "Structural and thermal analysis of asphalt solar collector using finite element method," Journal of Energy, vol. 2014, Article ID 602087, 9 pages, 2014.

[9] O. S. Omogoye, A. B. Ogundare, and I. O. Akanji, “Development of a cost-effective solar/diesel independent power plant for a remote station," Journal of Energy, vol. 2015, Article ID 828745, 10 pages, 2015.

[10] D. Borkowski and T. Wegiel, "Small hydropower plant with integrated turbine-generators working at variable speed," IEEE Transactions on Energy Conversion, vol. 28, no. 2, pp. 452-459, 2013.

[11] M. Sarvi, I. Soltani, N. NamazyPour, and N. Rabbani, "A new sliding mode controller for DC/DC converters in photovoltaic systems," Journal of Energy, vol. 2013, Article ID 871025, 7 pages, 2013.

[12] M. R. Islam, Y. G. Guo, and J. G. Zhu, "A high-frequency link multilevel cascaded medium-voltage converter for direct grid integration of renewable energy systems," IEEE Transactions on Power Electronics, vol. 29, no. 8, pp. 4167-4182, 2014.

[13] R. Watanabe, J.-S. Shin, T. Koseki, and H.-J. Kim, "Optimal design for high output power of transverse-flux-type cylindrical linear synchronous generator," IEEE Transactions on Magnetics, vol. 50, no. 11, Article ID 8202704, 2014. 
[14] C. Liu, H. Yu, M. Hu, Q. Liu, S. Zhou, and L. Huang, "Research on a permanent magnet tubular linear generator for direct drive wave energy conversion," IET Renewable Power Generation, vol. 8, no. 3, pp. 281-288, 2014.

[15] F. Wu, X.-P. Zhang, P. Ju, and M. J. H. Sterling, "Modeling and control of AWS-based wave energy conversion system integrated into power grid," IEEE Transactions on Power Systems, vol. 23, no. 3, pp. 1196-1204, 2008.

[16] T. Setoguchi, S. Raghunathan, M. Takao, and K. Kaneko, "Airturbine with self-pitch-controlled blades for wave energy conversion (estimation of performances in periodically oscillating flow)," International Journal of Rotating Machinery, vol. 3, no. 4, pp. 233-238, 1997.

[17] M. Takao, Y. Kinoue, T. Setoguchi, T. Obayashi, and K. Kaneko, "Impulse turbine with self-pitch-controlled guide vanes for wave power conversion (effect of guide vane geometry on the performance)," International Journal of Rotating Machinery, vol. 6, no. 5, pp. 355-362, 2000.

[18] M. Takao and T. Setoguchi, "Air turbines for wave energy conversion," International Journal of Rotating Machinery, vol. 2012, Article ID 717398, 10 pages, 2012.

[19] A. Thakker, J. Jarvis, and A. Sahed, "Quasi-steady analytical model benchmark of an impulse turbine for wave energy extraction," International Journal of Rotating Machinery, vol. 2008, Article ID 536079, 12 pages, 2008.

[20] B. Drew, A. R. Plummer, and M. N. Sahinkaya, "A review of wave energy converter technology," Proceedings of the Institution of Mechanical Engineers, Part A: Journal of Power and Energy, vol. 223, no. 8, pp. 887-902, 2009.

[21] L. Huang, J. Liu, H. Yu, R. Qu, H. Chen, and H. Fang, "Winding configuration and performance investigations of a tubular superconducting flux-switching linear generator," IEEE Transactions on Applied Superconductivity, vol. 25, no. 3, 2015.

[22] A. J. Garrido, E. Otaola, I. Garrido et al., "Mathematical modeling of oscillating water columns wave-structure interaction in ocean energy plants," Mathematical Problems in Engineering, vol. 2015, Article ID 727982, 11 pages, 2015.

[23] Z. Liu, Y. Cui, H. Zhao, H. Shi, and B.-S. Hyun, "Effects of damping plate and taut line system on mooring stability of small wave energy converter," Mathematical Problems in Engineering, vol. 2015, Article ID 814095, 10 pages, 2015.

[24] M.-J. Jin, C.-F. Wang, J.-X. Shen, and B. Xia, "A modular permanent-magnet flux-switching linear machine with faulttolerant capability," IEEE Transactions on Magnetics, vol. 45, no. 8, pp. 3179-3186, 2009.

[25] L. Huang, H. Yu, M. Hu, J. Zhao, and Z. Cheng, "A novel fluxswitching permanent-magnet linear generator for wave energy extraction application," IEEE Transactions on Magnetics, vol. 47, no. 5, pp. 1034-1037, 2011.

[26] L. Huang, H. Yu, M. Hu, C. Liu, and B. Yuan, "Research on a tubular primary permanent-magnet linear generator for wave energy conversions," IEEE Transactions on Magnetics, vol. 49, no. 5, pp. 1917-1920, 2013.

[27] V. D. Colli, P. Cancelliere, F. Marignetti, R. Di Stefano, and M. Scarano, "A tubular-generator drive for wave energy conversion," IEEE Transactions on Industrial Electronics, vol. 53, no. 4, pp. 1152-1159, 2006.

[28] J. F. Pan, Y. Zou, N. Cheung, and G.-Z. Cao, "On the voltage ripple reduction control of the linear switched reluctance generator for wave energy utilization," IEEE Transactions on Power Electronics, vol. 29, no. 10, pp. 5298-5307, 2014.
[29] E. S. Vidal, R. H. Hansen, and M. Kramer, "Early performance assessment of the electrical output of avestar's prototype," in Proceedings of the 4th International Conference on Ocean Energy (ICOE '12), Dublin, Ireland, October 2012.

[30] K. Lu and W. Wu, "Electromagnetic lead screw for potential wave energy application," IEEE Transactions on Magnetics, vol. 50, no. 11, Article ID 8205004, 2014.

[31] R. Salmon, Introduction to Ocean Waves, Scripps Institution of Oceanography, University of California, San Diego, Calif, USA, 2008.

[32] P. R. M. Brooking and M. A. Mueller, "Power conditioning of the output from a linear vernier hybrid permanent magnet generator for use in direct drive wave energy converters," IEE Proceedings-Generation, Transmission and Distribution, vol. 152, no. 5, pp. 673-681, 2005. 

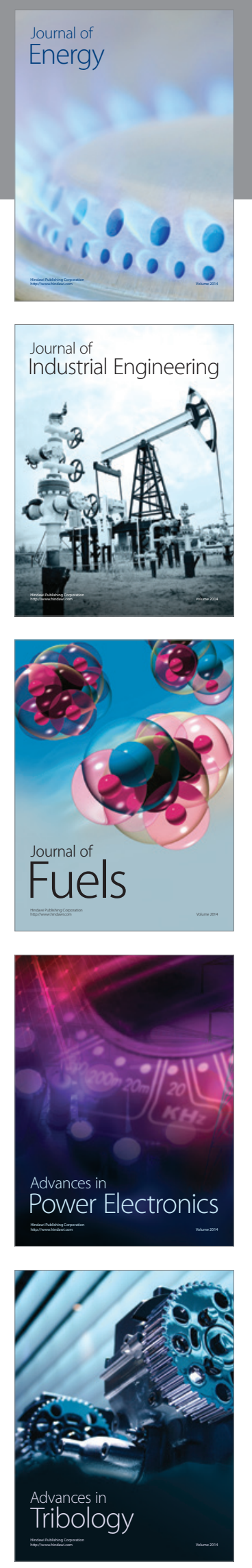
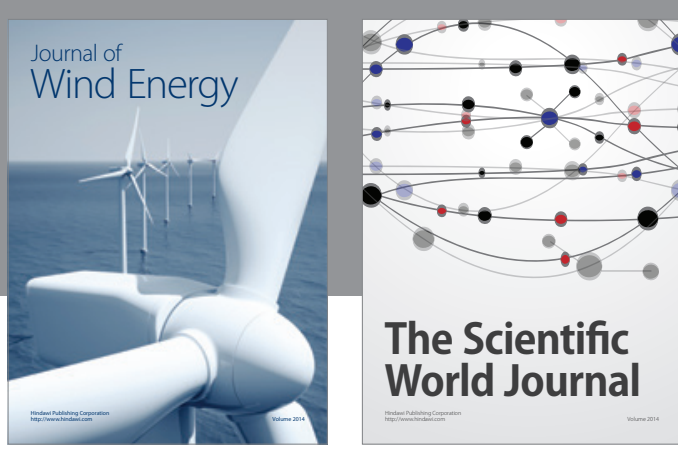

The Scientific World Journal
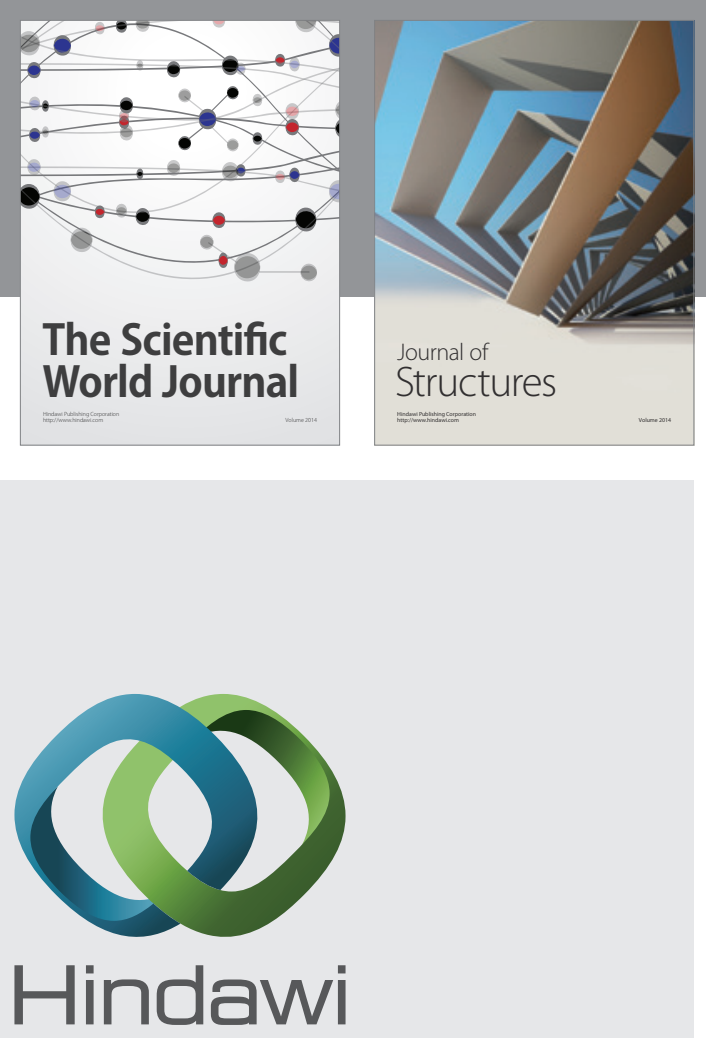

Submit your manuscripts at

http://www.hindawi.com
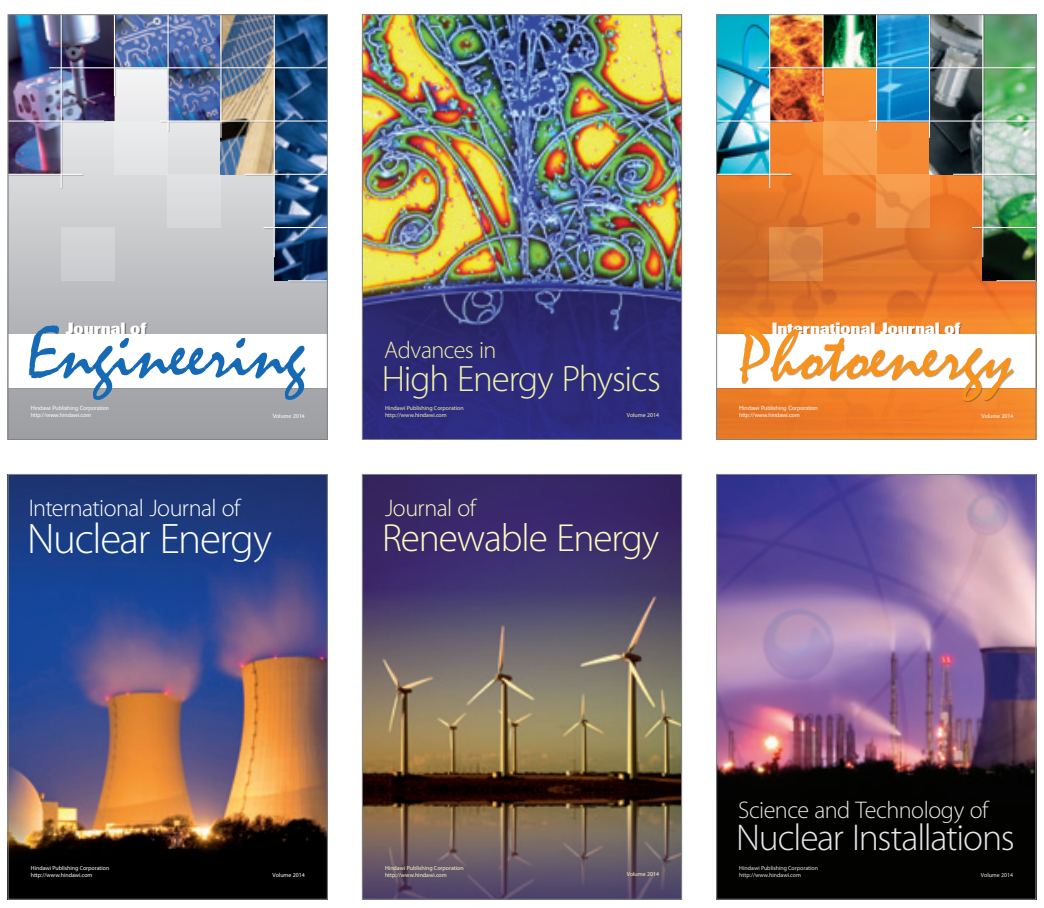
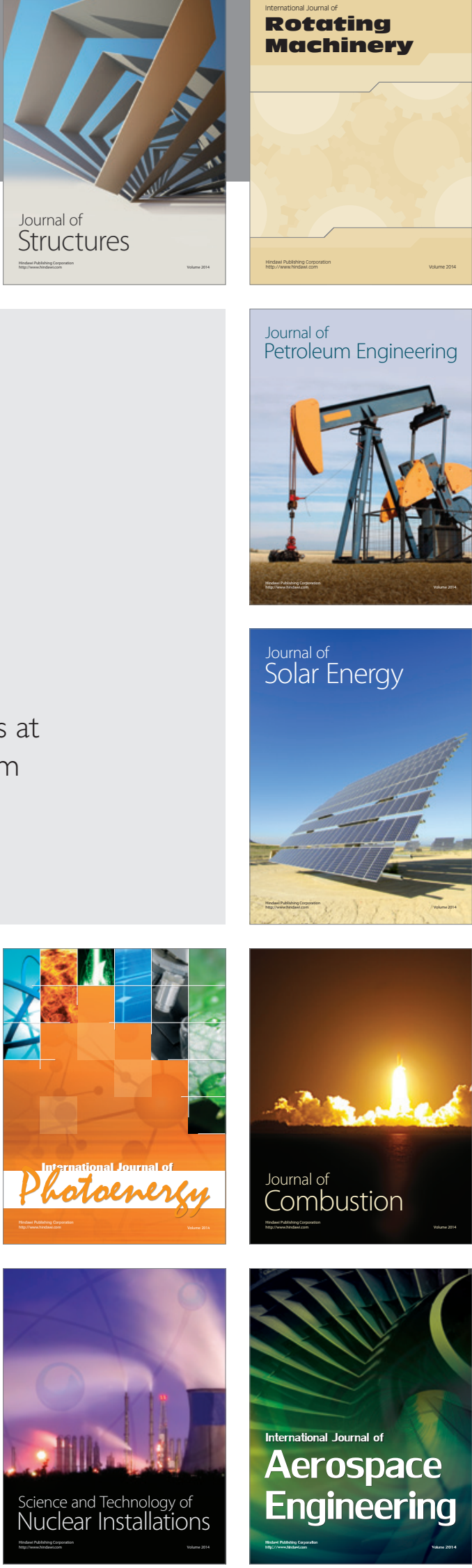